\title{
Interactive comment on "Is there a direct solar proton impact on lower stratospheric ozone?" by Jia Jia et al.
}

\section{Anonymous Referee \#2}

Received and published: 9 June 2020

The manuscript is a response to two previous studies by Denton et al. (2018a,b) which reported up to $10 \%$ average decrease of ozone at $\sim 20 \mathrm{~km}$ following solar proton events. Applying the same method (superposed epoch analysis) on different ozone observations (MLS, Aura), the current study arrive at a different conclusion: "SPE do not cause direct lower stratospheric ozone anomalies", which is corroborated by both observed and modeled case studies. The paper is well written and logically organized. Nevertheless, the manuscript still holds the potential for improvement, both in regard to the methods applied and the subsequent discussion.

Major revisions

1) Selection of events for the superposed epoch analysis: 
The superposed epoch analysis and case studies suffer from the lack of isolated SPEs. Several years have multiple SPEs occurring days apart. That implies that the period before the zero epoch time is already influenced by SPEs. Despite lower statistics, it would be more accurate to select one event, possible the first, within "the time frame". The same argument applies to the case studies, where one period could be marked with several onsets to avoid reproduction of the "same figure". Further, Figure 2 and the case studies would be more informative if the estimated ionization rates were added.

2) Ozone anomalies in respect to climatology:

Ozone anomalies are evaluated in respect to the climatology. The case studies demonstrates, as pointed out in the discussion, that the year to year dynamical variability is larger than the potential ozone impact. These conditions make it impossible to conclude that SPEs has zero impact on ozone. It is only possible to conclude that it is less than the year to year dynamical variability. It also demonstrates that the climatology is not necessarily a good reference frame to evaluate the SPE-impact. E.g. one of the strongest SPE, with onset 2012.03.07, has a strong positive ozone anomaly before the event which becomes less positive after the event. Hence it might be a reduction compared to the pre-storm values. Also, in Figure 2 (the superposed epoch analysis) single years such as January 2012 is evident as a significant positive anomaly below $40 \mathrm{~km}$. Hence, I speculate if the SPE impact would be better represented as a change relative to the $\sim 20$ days preceding the event. (Alternatively, events dominated by extreme dynamical anomalies such as January 2012 should be excluded from the superposed epoch analysis.)

3) Proton energy range in the WACCM model:

For the model runs, only protons with $<300 \mathrm{MeV}$ are included in the ionization rates. The respective energy range is therefore insufficient to account for the direct impact at $\sim 20 \mathrm{~km}$ (e.g. Turunen et al., 2009). Without a complete energy range impacting $20 \mathrm{~km}$, the discussion and the subsequent conclusion should reflect this limitation. It should

Printer-friendly version

Discussion paper 
also be noted that the 2005.01.16 case study are more pronounced in the observations compared to the model. This is particular true below $30 \mathrm{~km}$, which might imply that the model might underestimate the ionization rates, transport or chemical processes.

4) Ozone chemistry:

Would you expect the same chemistry to impact $\sim 20 \mathrm{~km}$ altitude as $\sim 70 \mathrm{~km}$ ? Is it still only EPP produced NOx and HOx than deplete ozone as described in the introduction, or are the chemical pathways of more complex deep into the lower stratosphere? E.g. Jackman et al. (2000) suggest that enhanced NOx values can lead to enhanced formation of the chlorine and bromine reservoir species $\mathrm{CIONO} 2$ and $\mathrm{BrONO} 2$, slowing down the 'ozone hole' formation chemistry in cold polar winters.

\section{Minor revisions:}

1 Introduction: Define altitude range of upper and lower stratosphere Line 12: define altitude range of lower stratosphere Line 13: Define acronym when "superposed epoch analysis" are first written (Line 12) Introduction: define altitude range of upper and lower stratosphere Line 18: "at many altitudes" be more precise Line 35-37: Outline where the results from WACCM is coming

2 Data sets Line 3: remove Microwave Limb Sounder as acronym is already defined Line 1/7 page 4: add $(\sim 50 \mathrm{~km})$ the first time you write $\sim 1 \mathrm{hPa}$

References, page 14, line 4: remove hyphen

Interactive comment on Atmos. Chem. Phys. Discuss., https://doi.org/10.5194/acp-2020-273, 2020. 